\title{
Against the act/omission distinction
}

\author{
Mark Dsouza* \\ University College London \\ Correspondence email: m.dsouza@ucl.ac.uk
}

\begin{abstract}
The act/omission distinction is widely thought of as being of foundational importance in the substantive criminal law of liberal states. While acts can be proper targets for criminal offences, it is thought that we should only exceptionally criminalise omissions. I argue against this piece of criminal law orthodoxy by showing that if we are careful to fairly compare acts and omissions qua targets for criminalisation, then none of the standard arguments in favour of the act/omission distinction convince. In fact, on close examination, there is little reason to think that an omission cannot perform the role played by the conduct element in the structure of a criminal offence, just as well as an act can.
\end{abstract}

Keywords: acts; omissions; criminalisation.

\section{INTRODUCTION}

Should acts tout court generally be considered better targets for criminalisation than omissions tout court? Plenty has been written on this question, both by those who think that the answer is yes, ${ }^{1}$ and those that disagree. ${ }^{2}$ But, with some notable exceptions, ${ }^{3}$ interest in it

I am grateful for the research support provided by Ms Nida Kadayifci. I am also grateful for the detailed feedback on drafts provided by James Chalmers, John Child, Andrew Cornford, Alex Sarch, Miles Jackson, Kevin Toh, Rory Kelly, Antony Duff, Sandra Marshall, Lindsay Farmer, Chloe Kennedy, J P Fassnidge and the anonymous reviewers.

1 T Honoré, 'Are omissions less culpable' in Responsibility and Fault (Hart 1999) 41-66; A P Simester, 'Why omissions are special' (1995) 1 Legal Theory 311.

2 J Glover, Causing Death and Saving Lives (Penguin 1977) 92-112; J Bennett, 'Morality and consequences' in S M McMurrin (ed), The Tanner Lectures on Human Values (University of Utah Press 1981) 45-116; M Tooley, 'Abortion and infanticide' (1972) 2(1) Philosophy and Public Affairs 37, 59-60; J Kleinig, 'Criminal liability for failures to act' (1986) 49(3) Law and Contemporary Problems 161.

3 For instance, S Sheffler, 'Doing and allowing' (2004) 114(2) Ethics 215; S Mathis, 'A plea for omissions' (2003) 22(2) Criminal Justice Ethics 15; V Tadros, 'Criminal omissions: culpability, responsibility and liberty' in Criminal Responsibility (Oxford University Press 2005) 182-211. 
had waned by the start of the twenty-first century, possibly in lockstep with increasing worries about overcriminalisation. After all, if we are worried about the criminal law reaching into aspects of our lives that should probably be outside its domain, then we have fewer reasons to question such limits upon criminalisation as are imposed by the act/ omission distinction (AOD), whatever its normative pedigree.

However, in a recent article, ${ }^{4} \mathrm{I}$ have argued that the criminal law can survive and thrive without the AOD, by adopting what I call the 'Remark-able Conduct Requirement' (RCR). Moreover, I suggest that the RCR limits the boundaries of the criminal law even more effectively than does the AOD. But while offering an alternative to the AOD, in that article I refrained from offering any argument against, or even addressing the normative defences of, using the AOD to structure the criminal law. ${ }^{5}$ If the RCR is a plausible alternative to the AOD, then this injects fresh life into the independently interesting debate about its place in criminal law.

In this article therefore, I return to the question of whether the AOD deserves its foundational place in criminal law theory and doctrine and argue that it does not. My argument proceeds through the following steps: section two is methodological - in it I offer suggestions for ensuring that any criminalisation-focused comparison between acts and omissions is fair and instructive. In section three, I argue that omissions are as capable of performing the role played by the conduct element in the structure of a criminal offence as acts are, and so, unless we are offered a convincing reason to systematically distinguish between acts and omissions in criminalisation theory, we should not. Finally, in section four, I examine the main reasons offered in support of employing the AOD in criminalisation decisions and show that they fail to convince. This conclusion should push us to reconsider the AOD's place in criminalisation theory orthodoxy, whether or not the reader is convinced that the RCR is a good replacement for it.

\section{STREAMLINING THE AOD ANALYSIS}

For any comparison of the normative significance of acts and omissions tout court to convince, it must compare like for like. Extraneous and contingent considerations should not be allowed to skew our thinking. In this section, I explain what this entails.

My interest here is in the AOD's role in questions of criminalisation. This context shapes the analysis in various ways.

M Dsouza, 'Beyond acts and omissions: remark-able criminal conduct' (2021) 41(1) Legal Studies 1. 


\section{What qualifies as an 'omission'}

Context shapes what qualifies as an omission. ${ }^{6}$ To see how, note first that the terms 'act' and 'omission' are ordinary language terms, and theorists on both sides of the debate on the significance of the AOD to criminalisation theory agree that, in ordinary language, not all nondoings are omissions. 7 For instance, it would be odd to say that I omitted to see infra-red light. Likewise there is something odd about accusing me of 'omitting' to log into a WiFi network if I don't realise that one is available. Nor does it make sense to say that I omitted to do my morning meditation if I never start my day with meditation. That holds true even if I have good reasons to start my day with meditation. Nobody - including those who think omissions are as plausible as acts qua candidates for criminalisation - argues that mere non-doings (i.e. non-doings that are not properly called 'omissions') are as plausible as acts qua candidates for criminalisation. We should therefore distinguish between mere non-doings and true omissions, so that we compare only the latter with acts. The most established way of doing so was first proposed by Feinberg, ${ }^{8}$ then adopted by Kleinig, ${ }^{9}$ and developed further in my own recent work. ${ }^{10}$ On this view,

$S$ omitted to do $a$ if and only if:

(1) S did not do $\alpha$;

(2) S had the opportunity to do $\alpha$;

(3) S had the ability to do $\alpha$;

(4) S had good reason to believe that he had the opportunity and ability to do $\alpha$; and

(5) a was reasonably expected of $S$, because

(a) S, or those in S's position, ordinarily do $\alpha$; or

(b) $\mathrm{S}$ had a responsibility to do $\alpha$; or

(c) S was obligated to do $\alpha$; or

(d) a was in some other way morally required of S.11

Here, conditions (2) to (4) relate to S's practical capacity to do the thing she allegedly omits to do. They explain why $\mathrm{S}$ does not 'omit' when she fails to see infra-red light, or fails to log into a WiFi network

6 In Dsouza (ibid) 7-9, I argue that the context also shapes what amounts to an 'act' (though I prefer 'commission'). However, for this article, a commonsense understanding of what amounts to an 'act' will suffice.

7 A Ashworth, Positive Obligations in Criminal Law (Hart 2013) 31; Simester (n 1 above) 319-320; Honoré (n 1 above) 47; Glover (n 2 above) 95; Dsouza (n 4 above) 3-7.

8 J Feinberg, Harm to Others (Oxford University Press 1984) 159-163.

$9 \quad$ Kleinig (n 2 above) 165.

10 Dsouza (n 4 above) 2-3.

11 Kleinig (n 2 above) 165. 
she does not realise is available. These conditions also apply in the criminal law - even if we assume that S's non-doings in these cases are 'conduct', there is a real sense in which they are non-voluntary 12 and therefore incapable of satisfying the criminal law's voluntary conduct requirement. This claim does not conceptually rule out inadvertent omissions - it is possible to be practically capable of doing something while absent-mindedly failing to exercise that capacity. This kind of nondoing may well be an omission, provided condition (5) is satisfied. ${ }^{13}$

Condition (5) - the 'reasonable expectation' requirement - reflects the fact that we use the word 'omission' to pick out non-doings that belie an expectation. In principle, the expectation may come from law, contract, morality, or simply an established routine, ${ }^{14}$ but here is where context matters - in determining whether condition (5) is satisfied, we should refer to expectations that are contextually salient. ${ }^{15}$ Different sets of expectations are relevant depending on the context in which we are inquiring about whether a given non-doing is an omission. We are interested in questions of criminalisation, and 'on any plausible normative theory of criminalisation, [it is] societal expectations... [that guide] thinking about what should be criminalised'. ${ }^{16}$ Accordingly, the contextually salient expectations are those of the ordinary member of society, who will know the moral norms and routines prevalent in the agent's society. Additionally, where the agent has special roleresponsibilities, the ordinary member of society will also know the expectations that we have of the sub-community of persons occupying the role being essayed by the agent. Non-doings that constitute deviations from these expectations, and that meet the other conditions identified above, are omissions. But non-doings that are not deviations, either because they comply with the relevant expectations, or because there are no relevant settled expectations, are not omissions. ${ }^{17}$ Since, in the criminalisation context, the relevant settled expectations can include even those arising from societal routines, the resulting sense of the term 'omission' carries no necessary pejorative connotations - it picks out note-worthy, but not necessarily even prima facie blameworthy non-doings. ${ }^{18}$

12 Ibid 164-166. Dsouza (n 4 above) 4. See also V Chiao, 'Action and agency in the criminal law' (2009) 15 Legal Theory 1, 16-18.

13 See, generally, Mathis (n 3 above) 21-23.

14 Kleinig (n 2 above) 164, 167, 169; Feinberg (n 8 above) 161-162; Simester (n 1 above) 320 .

15 Dsouza (n 4 above) 4-5.

16 Ibid 5.

17 Ibid 4-5. See also Kleinig (n 2 above) 164, 167, 169; Feinberg (n 8 above) 161162; Simester (n 1 above) 320.

18 Dsouza (n 4 above) 4. 
There is also a second way in which context shapes our use of the word 'omission'. Our interest is in questions of criminalisation, but we can be more specific than that. Our real focus is not on what might be thought of as 'net criminalisation', ie the net scope of criminal liability, after defensive pleas are considered. It is narrower: is it better for an offence stipulation, and more specifically, the conduct element therein, to be framed by reference to an act, or to an omission? This means that expectations (or exemptions from expectations) whose only role is to support defensive pleas, are not salient to the context of our inquiry.

Consider this example. A lecturer does not deliver a scheduled lecture because she was unwell. Even if (in some nightmare world) we were considering criminalising teaching-related lapses by academics, we might agree that this lecturer ought not to be criminally liable. We might think that, although the lecturer was ordinarily expected to deliver the lecture, in the extraordinary circumstances of her being unwell, she was not expected to deliver the lecture. There are two ways to argue in defence of this conclusion. We can say either that:

(a) the lecturer was under no net expectation to deliver the lecture on this occasion, and so, in not showing up to deliver the lecture, she belied no contextually salient expectation, and performed no omissive conduct. Hers was a mere non-doing, and that is why she ought not to be criminally liable. Or

(b) the lecturer was expected to deliver the lecture, and in not doing so, she did perform omissive conduct. Even so, she has a rationale-based defence available to her, and that explains why she ought not to be criminally liable.

On the first story, the fact that a lecturer is not, on an overall view of her situation, expected to deliver a lecture when unwell is salient to the identification of omissions in the context of criminalisation theory. It is therefore relevant to the AOD debate. On the second story, the same fact is relevant solely to a plea for a rationale-based defence. It is therefore not relevant to the AOD debate.

The second story is the one that better fits with the way in which modern liberal systems of criminal law are structured. Recall that our interest is in whether the lecturer's non-delivery of the lecture should be an omission for the purposes of the conduct element of a potential offence stipulation. In previous work, I have argued that, in modern liberal systems of criminal law, offence stipulations typically track imperative expectations that narrow our liberties, whereas defences typically track the permissions that are the exceptions to these narrowings. ${ }^{19}$ Therefore, in the context of modern liberal systems of

19 M Dsouza, Rationale-Based Defences in Criminal Law (Hart 2017) 47-88, especially at 86 . 
criminal law, when identifying omissions whose suitability for being the conduct element of a criminal offence we can fairly compare with acts,

[o]nly considerations that imperatively limit our default unfettered freedom to conduct ourselves as we please are relevant when identifying contextually salient expectations. Factors that permissively expand (by carving out exceptions to imperative limitations) our freedom to behave as we please, relate to rationale-based defences rather than to the conduct component of the actus reus of a prima facie offence. ${ }^{20}$

In our example, the imperative liberty-limiting expectation applicable to the lecturer is that she deliver her lecture. Her failure to deliver the lecture is therefore properly characterised as an omission, rather than a mere non-doing. Additionally, in the special facts described, a permissive liberty-expanding exception to this expectation also applies - she need not deliver the lecture when she is unwell. This gives her access to a rationale-based defence to liability arising from her omission to deliver the lecture. But it is a mistake to say that because there was no net expectation for her to deliver the lecture, there was no relevant omission.

In sum then, only non-doings that

(a) are 'performed' by persons exercising their practical capacity for voluntary control, and

(b) belie a contextually salient (ie stemming from societal morality or routine) imperative liberty-limiting expectation

are 'true' omissions. In general, only this subset of non-doings is even potentially of interest to conscientious liberal legislators considering questions of criminalisation. Any fair comparison of acts and omissions should exclude all other non-doings.

\section{Matters irrelevant to an offence's conduct element}

Within the criminal law, the AOD is relevant only to an offence's actus reus and, more specifically, to the conduct component of the actus reus. ${ }^{21}$ Accordingly, for my purposes, considerations going to other elements of an offence are extraneous. To be sure, they are relevant to overall liability outcomes and may be instructive in contexts other than an evaluation of the AOD's place in the criminal law, but, in this one, they must be excluded or neutralised (by ensuring that they affect both sides of the scale equally). Some such considerations to be excluded or neutralised include: 
(a) Differences in mens rea: an agent's advertence to, and mental attitude (intention, knowing indifference, or recklessness) towards, the conduct, consequences, or circumstances that constitute an offence's actus reus go to her mens rea, rather than to the inherent significance of the conduct-token. ${ }^{22}$ To guard against unbalanced intuitive pulls exerted by these factors, we should ensure that the conduct-tokens being compared were performed with identical mens rea states. ${ }^{23}$ Accordingly, we cannot usefully compare deliberate poisoning with careless failures to medicate, or the deliberate sabotaging of a parachute with a reckless failure to check it before offering it for use.

(b) Factors going to defensive claims: I mentioned previously the need to define omissions by reference only to imperative libertylimiting reasonable expectations. Doing this allows us to keep separate from candidate conduct-tokens any considerations that support the grant of rationale-based defences. These should be excluded when comparing the intrinsic significance of various conduct-tokens. Along the same lines, we should also ensure that possible defensive claims going to responsible agency and voluntariness are weeded out from our analysis. We can do so by ensuring that each of the agents in our examples is a sane adult, who is not engaging in involuntary conduct. Intoxication-related denials of mens rea can be excluded by ensuring that the agents in our examples are sober (or neutralised by ensuring that they are equally intoxicated!).

(c) Contingent systemic considerations: it may plausibly be thought that for practical reasons, prosecuting for omissions is generally harder than prosecuting for acts. Perhaps we lack the resources to prosecute all culpable omitters, but can prosecute people who criminally offend by acting. ${ }^{24}$ Perhaps it is easier to prove criminal acts than criminal omissions. Or perhaps a greater willingness to blame people for harmful omissions might make some feel that actively murdering someone is 'only' as bad as not

22 As I use it, the term 'conduct-token' is neutral as to whether the agent's conduct was an act or an omission.

23 Glover (n 2 above) 95.

24 See, for instance, Simester (n 1 above) 330. One can, however, dispute this claim, or think that the issue is overstated. For instance, a selective conception of an omission might reduce the number of omitters to more manageable proportions. Connectedly, if we think of what the criminal law already does as an acceptable proxy for 'manageable proportions', it is worth noting that the criminal law is quite comfortable with prosecuting several defendants for a single offence under its expansive doctrines of accessorial liability. 
contributing to the life-saving work of a charity. ${ }^{25}$ Even if true, these claims relate to practical reasons not to criminalise, rather than the question in which I am interested, viz whether acts and omissions tout court are equally eligible for criminalisation. For that reason, when debating the AOD tout court, we should not be influenced by such practical considerations.

\section{Unfair weights}

There still remain additional factors that might unfairly weight our analysis and should therefore be excluded or neutralised from any pairs of cases used to compare acts and omissions in the context of criminalisation theory. Since these need only be stated to see why they are extraneous to the AOD tout court, I will not discuss them in detail. They include:

(a) Unbalanced likelihoods of consequences: 26 we can guard against this by ensuring that the consequences required for the offence, if any, are equally likely to follow from the conduct-token, be it an act or an omission.

(b) Roles and relationships: since an agent's roles may influence what we expect of her in terms of conduct, 27 it makes little sense to compare cases in which the agents stand in different relations to the victims or the consequences (if any) of the conduct-token. So for instance, comparing a parent's act with a stranger's omission (or vice versa) unfairly weights our analytical scales. We should frame any examples used to analyse the AOD accordingly.

(c) Side-effects: we should also exclude from examples facts that tend to introduce bias in our intuitive assessments because they make one way of bringing about the outcome more psychologically horrific or repulsive (or humane and compassionate) than another. ${ }^{28}$ This is because it is simply not true that actively causing harm is inherently more horrific than passively causing it (or vice versa). Acts and omissions can bring about harms in equally horrific or banal ways. An act may be the compassionate alternative to an omission, despite involving direct physical contact with the 'victim' - consider consensual mercy killings, or

25 Glover (n 2 above) 110-111 discusses this extremely speculative objection and is as unconcerned about it as I am.

26 Glover (n 2 above) 98.

27 Kleinig (n 2 above) 170; Honoré (n 1 above) 65.

28 Glover (n 2 above) 99 calls these 'side-effects'. He illustrates this error by pointing to the unfairness of comparing the chancellor who cuts the budget allocation for pensions, thereby causing the death of several pensioners, with the chancellor who just takes a machine gun to the same number of pensioners. See also Bennett (n 2 above) 74 . 
vets who put down beloved but seriously ill pets. But, equally, acts may be evil and horrific despite the perpetrators being remote from the victims - consider people who use drones or longrange missiles to kill others thousands of miles away. And we can easily think of cases in which, depending on the circumstances, omissions can be cruel, or compassionate, and may be perpetrated in physical proximity to, or far away from, the victim. Therefore, in comparing acts and omissions tout court, we should exclude or neutralise such factors.

One might object that, if we exclude all these factors, we are left only with fairly unrealistic examples - Honoré uses the term 'bizarre',29 and Simester prefers 'thoroughly artificial' and 'extraordinary'. 30 The worry is that the strangeness of these examples might render our moral instincts untrustworthy and lead us to erroneous conclusions. ${ }^{31}$ This is possible, but far from inevitable. The examples with which we are left should be seen as thought experiments, which do not have to be realistic to be enlightening. In fact, plenty of thought experiments have, despite their unrealistic nature, contributed significantly to philosophical progress. ${ }^{32}$ Indeed, the extraordinariness of our thought experiments may well make our intuitive responses more trustworthy, since they are less likely to be influenced by received wisdom. In sum, provided that we are mindful of the limitations of our thought experiments, they can be instructive.

29 Honoré (n 1 above) 52, 62.

30 Simester (n 1 above) 326-327.

31 Honoré (n 1 above) 63 and Simester (n 1 above) 327. Interestingly, the conclusion that both anticipate us reaching is that, insofar as the criminal law in concerned, acts and omissions are similar.

32 For example, Plato's cave, Descartes' evil demon, and Hobbes' state of nature. For a very interesting analysis of how thought experiments can be an aid to reasoning, see Daniel C Dennett, Intuition Pumps and Other Tools for Thinking (Penguin 2014). Besides, theorists, including many of those who have raised the objection to which I am responding, have themselves engaged in occasional bouts of 'trolleyology', some of which I reference later in this article. The most common version of the Trolley problem is fanciful enough as it is - it involves a runaway trolley hurtling down a track towards a person or persons who will be killed unless our protagonist pulls a lever to divert the trolley to another track such that it will kill others. See P Foot 'The problem of abortion and the doctrine of double effect' (1967) 5 Oxford Review 1 at 3; J J Thompson 'The trolley problem' in Essays on Moral Theory (Harvard, 1986) 94. But there are plenty of even more fanciful variations of the Trolley problem that regularly feature in the literature. 


\section{A DEFAULT POSITION ON THE AOD}

Based on the way in which a criminal offence is structured, we have a positive, albeit defeasible, reason to start from a position of doubt about the AOD in criminalisation theory. To see this, recall that, in doctrinal criminal law, a person is liable to a criminal conviction if she is

(a) a responsible agent (ie she meets the law's capacity conditions of age, sanity etc), who is

(b) capable of volitional conduct (so, not in an automatic state), and is

(c) exercising that capacity for volitional conduct (so, not involuntarily tripping, falling, or moving reflexively), to

(d) perform the offence's actus reus, with the

(e) necessary mens rea for it, and

(f) without any justification or excuse.

The actus reus - point (d) above - may include elements of conduct, consequence and circumstance. ${ }^{33}$ The relevant question in the context of criminalisation theory is whether, in general, acts are better suited to satisfy the conduct element of the actus reus of a criminal offence than omissions.

We can answer this question by identifying the role that the conduct element plays in a criminal offence. Based on its place in the structure of a criminal offence, it appears that the conduct element (sometimes in combination with specified circumstances, or consequences, or both) is what makes an instance of a responsible moral agent exercising volitional control over herself, of interest to others. It does this by somehow altering the baseline state of the outside world. This baseline state is not one in which nobody does anything that affects others; that would be a wholly unnatural baseline, completely disconnected from the intensely social nature of our lives. Instead, the relevant baseline is one in which people interact with others in ways that are reasonably expected. These expectations may come from (legal or moral) duties, but they need not. Our reasonable expectations of each other may also stem from ways of interacting in society that are so commonplace as to become routine - things like forming (or not, depending on where you are) a queue, standing on the left on the escalator, mumbling an apology when accidentally brushing against someone, or nodding a head to acknowledge someone else's presence in a confined space. In other words, social etiquettes and routines can also give rise to reasonable expectations.

The similarity between the reasonable expectations I have just described and those to which we refer when identifying omissions 
relevant to questions of criminalisation is unmistakeable. And it is not a coincidence. The factors that distinguish a true omission from a mere non-doing for the purposes of criminalisation questions are exactly the same factors that make any conduct of potential interest to the criminal law. ${ }^{34}$ It is the deviations from societal understandings and patterns of interaction - what Kleinig calls 'conventional manifestations of a social milieu' 35 - that cause our world to change in ways that are interesting enough to call for further inquiry. These deviations, therefore, are capable of satisfying the conduct element of a criminal offence. Depending on the nature of the offence that we are thinking about enacting, we may also require that the conduct be performed in specified circumstances, and/or with specified consequences so as to satisfy its actus reus. But if there is no conduct that deviates from the natural baseline of unremarkable social interactions, there is nothing to investigate. True omissions, by definition, are deviations from the natural baseline of unremarkable social interactions. Prima facie therefore, they are capable - certainly as capable as acts are - of satisfying the conduct element of any offence we might wish to create.

The onus therefore should be on those that insist on systematically distinguishing between acts and omissions in criminalisation-related contexts to set out a convincing reason for us to agree with them. In the next section, I consider the main arguments that have been offered in support of the AOD.

\section{DEFENCES OF THE AOD}

Having identified what we must do to fairly compare acts and omissions in the context of questions of criminalisation, and determined that by default we should be sceptical of the significance of the AOD to questions of criminalisation, we are now ready to examine the arguments in support of systematically distinguishing between acts and omissions in criminalisation decisions. I do not propose to consider what Honoré calls 'optimising theories'36 here, since, firstly, they are generally raised to argue against, rather that support, the AOD, and, secondly, they are built upon an implausibly utilitarian view of our duties which has largely fallen by the philosophical wayside. At any rate, no familiar liberal criminal justice system accepts the premise of such theories, viz that one must behave (including when making decisions about

34 This is why I argue, in Dsouza (ibid) 7-9, that not all doings are 'true' acts either though for more precision, in that context I use the term 'commissions'.

35 Kleinig (n 2 above) 169.

36 Honoré (n 1 above) 44-45. See also Tadros (n 3 above) 185-186. 
what to criminalise) so as to optimise overall welfare, which in turn is calculated by adding up the individual welfares of each person. 37

Current theoretical battles about the AOD are fought mainly on four battlegrounds, viz authorship/responsibility, causation, wrongness/ culpability, and liberty.

A survey of these arguments suggests that they do not succeed in defeating the structural reason we have to doubt the AOD.

\section{Authorship and responsibility}

Is there a sense in which, when we author the stories of our lives by interacting with our environment and other people, we do so primarily through our acts, and only secondarily through our omissions? Several leading theorists think so (though when making this claim, they sometimes switch between the language of 'responsibility' and 'authorship'). Simester, for instance, argues that 'people normally have a sense of their own identity as individual persons in some sort of relationship to the world, whose characters are manifested in terms of what they do and do not do'. 38 He agrees with Honoré39 that a person who does something is its 'primary (even paradigmatic) author'. ${ }^{40}$ Scheffler ${ }^{41}$ and Tadros 42 also concur that doing has primacy over not doing. But all four accept that we can also author our lives by omissions. ${ }^{43}$ They accept, that is, that I can author both my acts and my omissions.

Simester and Tadros offer no sustained independent arguments for the supposed primacy of authoring by acting rather than by omitting. Honoré supports his position by asserting that

[a] close study of causal language and thought suggested that the reason why movements feature so prominently in our assessment of responsibility is that we have a picture of the world as a matrix into which, by our movements and especially our manipulation of objects, we introduce changes. ${ }^{44}$

37 Ibid 44-45.

38 Simester (n 1 above) 329.

39 Honoré (n 1 above) 52-53, especially at 53, where Honoré asserts that 'the difference between doing and not-doing is the notion of intervening in the world so as to bring about change; and that at a secondary level this notion extends to the interruption of human routines' (emphasis supplied). See also Scheffler (n 3 above) 221-225.

40 Simester (n 1 above) 329.

41 Scheffler (n 3 above) 220-224.

42 Tadros (n 3 above) 196 suggests that a person whose culpable failure to assist $\mathrm{V}$ results in V's death at the hands of $\mathrm{X}$ is 'secondarily rather than primarily responsible for the death'. See also Scheffler (n 3 above) 225.

43 Simester (n 1 above) 329; Tadros (n 3 above) 192-196; Honoré (n 1 above) 53; Scheffler (n 3 above) 218.

44 Honoré (n 1 above) 52. 
Unhelpfully though, the close study to which Honoré refers, is just four pages in Hart and Honoré's Causation in the Law, 45 in which the proposition concerned is asserted and supported only by intuition.

Now it is true that much of our language of causation is act-normative. It is also possible that this points to some fundamental truth about how we humans view our interactions with the world, which we should build into, rather than weed out of, our analysis of our conduct. But before committing to that position, let us take a step back. Language is culturally relative. It is shaped by several factors that have nothing to do with how we, as humans, are fundamentally hardwired to make sense of our interactions with our environment. 46 Thus, words and figures of speech are unreliable indicia of fundamental truths about humans. The empirical plausibility of the claim that we usually use actnormative language to describe our conduct proves little about how we, as humans, are fundamentally hardwired to author the stories of our lives. Our language patterns might just as plausibly be shaped by the regularity with which we use different modes of conduct to author the stories of our lives. Perhaps (though there is room for doubt about this) we more frequently author our life stories by acting than by omitting. But the relative frequency with which we use one mode of authoring the stories of our lives does not establish its hardwired primacy, any more than the relative prevalence of right-handedness in humans establishes the hardwired primacy of right-handedness. It seems mistaken to assume that contingent facts about the state of our causal language yield up fundamental truths about how we author our lives.

But maybe the authorship/responsibility theorists could make do with the more modest claim that our language says something about how we are culturally hardwired in our societies to author our life stories. But even that claim seems incapable of being proved merely by the frequency with which we use certain words or phrases. We would need much more argument about what it means for something to be culturally hardwired (as opposed to just 'more common') in our societies, and why we should think that something like authorship of our life stories can be culturally hardwired. We would also need empirical evidence for the claim that authorship by acting is in fact so hardwired. In sum, we would need much more than is available in Honoré's argument.

Scheffler has another way of arguing for this claim. He says that:

to see oneself as subject to norms of individual responsibility is already to draw a normatively relevant distinction ... between primary and secondary manifestations of one's agency ... [since it is] ... to see oneself

H L A Hart and T Honoré, Causation in the Law 2nd edn (Oxford University Press 1985) 28-32.

46 Though of course such factors might also shape our language. 
as having reason to bring one's conduct into conformity with those norms ... [and] bringing one's conduct into conformity with norms of individual responsibility is itself something that one does, and not something that one merely allows to happen. It requires marshalling the full resources of one's agency, including one's capacities for deliberation, choice, and action ... If one sees oneself as subject to a standard of responsibility and holds oneself to that standard, then one sees oneself as responsible for exercising a kind of overall regulative control of one's conduct, and the exercise of such control is itself a full-fledged expression of one's agency ... [F]rom the perspective of the individual agent, the internalized demand that one live up to a standard of responsibility always presents itself as a demand that one do something, namely, that one regulate the exercise of one's agency in conformity with the relevant norms. 47

But there are a few worries with Scheffler's argument. It appears at heart to boil down to the fact that the language of bringing (one's conduct into conformity with norms), exercising (overall regulative control of one's conduct), and regulating (the exercise of one's agency) is active, rather than passive. But as previously noted, in itself, this fact about our language is far from conclusive. Active verbs can often be substituted with passive verbs, if not in English, then in other languages. In any case, one can also exercise regulative control of one's conduct by choosing not to do something, and one can also regulate the exercise of that agency by choosing not to exercise it, or by choosing to exercise it to do nothing.

Perhaps this last point cannot be made in respect of bringing oneself into conformity with norms of individual responsibility. But even there, seeing oneself as subject to the norms of responsibility must surely also entail seeing oneself as having reason not to deviate from one's existing conformity with those norms. This would suggest that being or remaining in conformity with those norms is also at least as important as bringing oneself into conformity. And not deviating from our existing conformity with such norms is hardly something one 'does' - it is something that one actively refrains from doing, by continuing to maintain conformity. We could say that we are at least as much human beings as human doings.

Not just that; unless we make the questionable assumptions that new-borns are a moral tabula rasa, and that all moral learning is conscious, we must have some initial conformity with these norms, and some of our 'bringing ourselves into conformity with the norms' must be done unconsciously and without the marshalling of the resources of one's agency that Scheffler associates only with doing. Seeing oneself as subject to norms of individual responsibility then seems to involve some agential doing (ie bringing oneself into conformity with the norms), some agential refraining (ie not straying from existing

47 Scheffler (n 3 above) 221-222. 
points of conformity with the norms), and some non-agential drifting into and out of patterns of conformity with the norms. From this richer perspective, seeing oneself as subject to norms of individual responsibility does little to establish the primacy of acting to author our lives over doing the same by omitting.

Since Scheffler's conclusion about the primacy of commissive authoring over omissive authoring is premised on the specialness of 'doing' in accepting that one is subject to norms of individual responsibility, it falls with that premise.

But even if we reject the primacy claim, Simester suggests another way of defending the AOD on the basis of authorship. Referring to the Trolley Problem, he agrees with Malm ${ }^{48}$ that we cannot justify pulling the lever and causing one person's (Sam's) death, even when not pulling the lever would result in another person's (Tom's) death. He, quite rightly, does not adopt Malm's reasons for reaching that conclusion Malm's argument relates to not having a good enough reason to transfer the impending harm from Tom to Sam, and that is an argument about rationale-based defences, rather than the conduct component of the actus reus of an offence. Instead, he claims that the agent 'can say to Tom's parents: I do not have to justify my not saving Tom, for his death had nothing to do with me.' $49 \mathrm{He}$ adds that were an agent to intervene and divert the trolley towards Sam, she would make Sam's death a part of her life, an aspect of her relationship with the world that is distinctive of her and not of anyone else. The agent would still be susceptible to moral assessment in respect of her failure to save Tom, since she could have saved Tom. However, that Sam would have died had she saved Tom 'counts as an important secondary reason: it underpins [the agent's] denial that there was a good enough reason for [her] to get involved'.50 In this analysis, the agent's reason to get involved is not good enough because of countervailing reasons not to get involved. But it is unclear, from the perspective of authorship, why the purported presence of good reasons not to get involved is relevant. To rely on good reasons to not do something one has other reasons to do, is to rely on a rationale-based defence rather than to deny authorship entirely. If I promise to meet you for dinner, but my daughter falls seriously ill just before our appointment, I certainly have a good explanation (or rationale-based defence) for my absence at lunch, but it seems odd to deny that I authored my absence. That would be to deny that the empty chair at the dining table had anything to do with me. For this reason, I am not convinced that Simester manages to sidestep the problem he

48 H Malm, 'Killing, letting die, and simple conflicts' (1989) 18(3) Philosophy and Public Affairs 238, 246-247.

49 Simester (n 1 above) 331.

50 Ibid 331-332. 
anticipated with adopting Malm's argument. Moreover, it is not clear to me why an agent who is uniquely placed to intervene and divert the trolley away from Tom, but who chooses not to intervene, does not thereby make Tom's death a part of her life to the same extent as she would make Sam's death a part of her life by intervening. Since she was, ex hypothesi, the only person who could have saved Tom, her choice not to do so must surely also be an aspect of her relationship with the world that is distinctive of her and nobody else.

If we treated authorship by doing as being on par with authorship by non-doing, then even accounting only for 'true' omissions, we would have a much larger pool of authors for each harm that occurs, because it is often true that more people occasion a harm by their omissions than by their acts. But fears of a worrying dilution of individual authorship are misplaced, because as both Simester ${ }^{51}$ and Bennett 52 note, the larger the number of culpable omitters, the larger the number of wrongs committed in respect of the same harm, and different wrongdoers continue to author their own separate wrongdoings.

So what are we left with in terms of authorship? If we understand authorship by reference to how we write and recount the stories of our lives, it seems clear that we author our doings, and nobody seriously denies that we author at least some of our non-doings. And it's not just our omissions that we author - we also author our chosen nondoings of things we were not expected to do. In telling the story of my life, I can sensibly say, 'I didn't call tails, but I wish I had', or, 'I saw that lottery ticket, but didn't buy it'. In this wide sense, authorship is not very instructive - it is just a minimal, necessary but not sufficient, qualification requirement for us to be interested in an agent in respect of some conduct. It generates no reason to distinguish between our doings and our non-doings, and it certainly cannot support the distinction between acts and omissions in the criminal law's conduct requirement for the actus reus of an offence.

\section{CAUSATION}

Moore has a different approach to defending the AOD. He argues that while acts cause consequences, omissions do not - they are merely failures to prevent consequences. ${ }^{53}$ This argument seems naturally confined in its application to instances in which consequences matter. Since we are interested in questions of criminalisation, this argument

51 Ibid 328-329.

52 Bennett (n 2 above) 84. Bennett pithily concludes that: 'Morally speaking, there is no safety in numbers,'

53 M Moore, Act and Crime (Oxford University Press 1993) 267-278. Feinberg calls this the 'restricted causation claim'. Feinberg (n 8 above) 165. 
seems most suited to defending the AOD in respect of potential offences in which there is a consequence element. It would appear to have less to say about potential conduct-only offences such as dangerous driving.

But even in respect of prospective offences with consequence elements, despite its initial plausibility, the argument from causation can be set aside fairly quickly. As has been frequently pointed out, 54 while Moore's somewhat mechanical approach to causation may apply in some domains, in the law at least, the ascription of causal responsibility is a normative as well as mechanical issue. Therefore, in law (and in ordinary speech), it is perfectly commonplace for us to reserve the language of causation to pick out the most salient ingredients in the occurrence of an event - even if they are omissive as their causes. And it is precisely when some non-doing is an omission in the sense previously described - when it belies a reasonable expectation - that it is 'salient', and worth singling out as conduct that causes a consequence. As such, the argument from causation generates no reason to distinguish between acts and true omissions in criminalisation theory.

\section{Wrongness and culpability}

A third approach to defending the AOD is to say that one who brings about harm by an act ought to be blamed more than one who brings it about by an omission. This claim is fleshed out in two ways.

The first is to argue that there is a difference in the wrongness of harming by acts and harming by omissions. Honoré argues that harming by an act affects our interest in security directly, whereas harming by an omission either (1) affects only a secondary, less important, interest in the expectation of improvement, or (2) affects the primary interest in security only indirectly as a failure to react to someone else's security interest-threatening acts (which Honoré calls 'worsening interventions'). 55 According to Honoré, we live

in a relatively stable (as it were, Newtonian) world, in which people and objects on the whole continue as they are unless something intervenes to change them. People reasonably attach importance to this continuity since their survival and that of others depends on it ... Security in this sense is therefore a prime human value, and any conduct that threatens to change it for the worse a prime evil ... This helps to explain ... why positive harm-doing is on the whole viewed as worse than harmful abstention, which threatens our security interests only indirectly. 56

Simester (n 1 above) 315-316; Kleinig (n 2 above) 174-188; Feinberg (n 8 above) 172-181; Bennett (n 2 above) 84-86; Honoré (n 1 above) 50-51; A F Sarch, 'Knowledge, recklessness and the connection requirement between actus reus and mens rea' (2015) 120 Pennsylvania State Law Review 1, 40-41.

55 Honoré (n 1 above) 63-66.

56 Ibid 63-64. 
For Honoré then, our interest in security boils down to our interest in a certain type of expected Newtonian continuity. Newtonian continuity dictates that things at rest will ordinarily continue to be at rest. By analogy, Honoré argues that we have a security interest in the world continuing as it is. Acts disturb the existing state of the world, whereas omissions do not. Hence, says Honoré, tout court acts are of greater interest to the criminal law than omissions.

But, of course, Newtonian continuity also dictates that things in motion will ordinarily continue in motion. In terms of Honoré's own analogy then, our security interests must also extend to the dynamic features of our world - what we are entitled to expect of others. After all, the stability of my world is also disturbed when my regular bus unexpectedly does not arrive, or my supermarket has no milk in stock. ${ }^{57}$ To be fair, Honore is open to this claim. ${ }^{58}$ So let us substitute into Honoré's argument this richer picture of the world - one with both static and dynamic elements - and consider what an interest in the stability of that world would entail. Our interest in security would now include an interest in not having what Kleinig called our 'reasonable expectations' 59 belied. But, if that is the case, then the first variant of Honoré's wrongness argument relates only to non-doings that do not properly count as 'true omissions' (at least as I use the term), ${ }^{60}$ since all omissions belie a reasonable expectation to act and, therefore, affect what Honoré calls a security interest. And, even if we take Honoré to be working with a different understanding of the term 'omission', his argument cuts across the AOD. Acts can affect an interest in the expectation of improvement (as might happen if one actively prevents a lifeguard from saving a drowning person), and omissions might sometimes plausibly affect our interest in security (as when, by not doing anything, one effectively takes away a drowning person's last chance of survival). ${ }^{61}$

57 P Smith, 'Legal liability and criminal omissions' (2001) 5(1) Buffalo Criminal Law Review 69, 96-97.

58 Honoré (n 1 above) 64 accepts that omissions are threatening 'when security has come to depend on homeostatic routines'. See also Simester (n 1 above) 317318.

59 Kleinig (n 2 above) 165.

60 And it is not at all clear to me that Honoré uses the term in a different sense. This is how he sets out his understanding of the term 'omission': 'Omissions are ... those not-doings that violate norms. Norms are divided for this purpose into ordinary norms and norms that impose distinct duties ... Omissions that violate distinct duties may be termed distinct omissions.' Honoré (n 1 above) 43. Notice that for Honoré, omissions are the violations of norms that may be either distinct norms, or ordinary norms.

61 Simester (n 1 above) 322. See also Glover (n 2 above) 96-97. 
Consider the other variant of the wrongness argument that Honoré presses - that omissions are less wrong since they are failures to intervene against someone else's worsening intervention. ${ }^{62}$ Again, if failures to act are only properly called omissions when they threaten someone's security interest by belying a 'reasonable expectation' of action, then it is simply not true that genuine omissions are 'mere' failures to respond to another's worsening intervention. They are themselves worsening interventions. And once more, even if Honoré is using the term 'omission' in some different sense, his argument does not convince, since one also omits in cases where the worsening intervention follows the anomalous non-doing (as when burglary follows a failure to lock a door), or where there was no prior worsening human intervention (as in a failure to rescue a drowning person). 63

Consider now the second way of arguing that one should be blamed more when harming by act than by omission. This is the argument from culpability - the suggestion that harming by act is more blameworthy than harming by omission. Tadros makes this argument by asking us to consider two types of omissions cases, and arguing that in both, our moral intuitions suggest that acts are more culpable than omissions. 64

First, Tadros compares our intuitions in cases involving killing, and letting die. He argues that because killings tend to provoke greater moral outrage than even preventable deaths, this suggests that killing (ie causing death by an act) is more culpable than letting die. ${ }^{65}$ Even if we share these intuitions, Tadros' conclusion does not follow. The intuitions relied upon are those of third parties - persons who were not the unfortunate victims in Tadros' hypotheticals. It is not clear that third parties' intuitive feelings of moral outrage or resentment toward the putatively blameworthy agent accurately track her culpability. As Simester points out, 66 killers are more threatening de futuro than those that let die, and that might tend to augment our moral outrage

\footnotetext{
62 Honoré (n 1 above) 64.

63 Simester (n 1 above) 323-324.

64 Tadros (n 3 above) 186-188.

65 Ibid 187.

66 Simester (n 1 above) 321.
} 
towards killers. But these threat perceptions do not reflect on an agent's culpability for conduct she has already performed. 67

Perhaps instead of referring to survivors' moral outrage when assessing the protagonist's culpability, we should consider our intuitions about how much the victim may legitimately blame the protagonist. This seems relevant because at the criminalisation stage, when we stipulate an offence's actus reus (including its conduct component, be it an act or an omission), we are strongly motivated by, and sensitive to, the harm (if any) caused to the victim. In homicide cases, like those Tadros invokes, most would agree that the central victim is the deceased, 68 rather than those that survive her. Hence, we should be more interested in the victim's perspective than those of the survivors. In Tadros' comparison between killing and letting die, at the point of death, I am not confident that the victim blames D1 who intentionally drowns her, more than she blames D2 who, despite being able to rescue her safely and easily, deliberately decides not to, with the intention 69 thereby that she drown. Therefore, I find this argument unconvincing.

Let us turn instead to the other set of cases that Tadros considers. Tadros argues that we intuitively think that one who kills should feel greater regret than one who lets another kill (even if she could easily have prevented the killing), and therefore we have reason to believe that the former is more culpable than the latter. ${ }^{70}$ Again, this does not follow. Assuming that both the killer and the non-intervener conducted themselves as they did in order to cause the death, it is not clear to me that they ought to feel different amounts of regret. Further, Tadros does not explain why we should think that the regret that one ought to feel mirrors one's culpability. In fact, we regret all sorts of things for

67 That said, if we are more threatened by actors than omitters, we might conclude that acts are worse than omissions on purely consequentialist grounds. My thanks to James Chalmers for this suggestion. Note that, strictly, this is not an argument about the comparative culpability of acts and omissions. Moreover, I doubt that this 'reactive attitude' analysis carries over into consequentialist argument - consequentialists tend to be more interested in actual consequences than felt consequences. That we feel more threatened by actors than omitters does not imply that we are more threatened by them. And finally, while we may plausibly think that actors whose conduct was accompanied by subjective mens rea outnumber omitters whose conduct was accompanied by subjective mens rea, the converse seems likely in respect of negligent agents. All in all, it is far from certain that cumulatively, actors are a significantly worse de futuro threat than omitters.

68 Feinberg (n 8 above) 79-83. Along similar lines, see R A Duff, The Realm of Criminal Law (Oxford University Press 2018) 77.

69 Recall that we can only fairly compare agents acting with the same attitudinal states towards the actus reus of the offence.

70 Tadros (n 3 above) 187-188. 
which we do not deserve blame. I might regret calling heads instead of tails, but it seems strange to seriously blame me for calling a coin-toss incorrectly. This argument too fails to convince.

A better indicator of the protagonist's culpability might be our intuitions about how much she should blame herself. After all, why consider regret when our interest is in blame? In that spirit, consider two mothers who negligently cause the deaths of their equally beloved infants in different ways. ${ }^{71}$ Anjana carelessly bumps into her child, knocking her over, whereas Brinda leaves her child in the car while buying groceries, but carelessly forgets to roll down a window. It is not clear to me that Anjana would or should blame herself any more or less than Brinda. (Nor for that matter is it clear to me that the infant victims, had they been capable of sophisticated moral assessments, would blame their respective mothers any differently.) In short, there is little in Tadros' intuition-based arguments to convince us that acts tout court are more culpable than omissions tout court. In fact, an intuitive case can be made for their equivalence.

\section{Liberty}

A fourth approach to defending the AOD is the argument from liberty. Prohibiting an act, the argument goes, is more liberty-respecting than prohibiting an omission, and so the norm in the criminal law ought to be prohibiting acts rather than omissions. ${ }^{72}$ Furthermore, since duties to act are often contingent upon us noticing the circumstances in which others find themselves (such as being in imminent danger), creating such duties gives others the power to unilaterally and unexpectedly create obligations for us by, for instance, putting themselves in danger. This unfairly limits our autonomy and ability to independently plan and live our own lives and, potentially, has a chilling effect on activities, during the performance of which, one might encounter duties to act. ${ }^{73}$ And the objection is not just to giving other people the power to impose duties upon one - even when the state forces us to act (and even if it is in service of a good goal) this undermines our wellbeing, since wellbeing depends on our goals being our own, rather than imposed upon us. ${ }^{74}$

71 Note again that we are comparing like for like. In both cases, the agents occupy the same roles in relation to their victims, they have and exercise the capacity for volitional conduct, their impugned conduct is inadvertent, and it results in the same level of harm.

72 Bennett (n 2 above) 77-78, M Moore, Placing Blame (Oxford University Press 1997) 278-283.

73 Simester (n 1 above) 335. A Ashworth, 'The scope of criminal liability for omissions' (1989) 105 Law Quarterly Review 424, 430.

Simester (n 1 above) 333-334. 
After all, forcing us to act in ways in which, morally, we ought to act anyway makes it harder for us to demonstrate virtue; doing something good because we are forced to do it, is not nearly as virtuous as freely choosing to do it. 75

Now it is undoubtedly true that there are infinitely more ways to not do something than to do it, so it seems plausible that a prohibition on the former (ie criminalising the failure to do the thing) will be more liberty-limiting than a prohibition on the latter (ie criminalising doing the thing). But it is important to be clear about the magnitude of difference in liberty-limiting on the two approaches. The argument is (or at least, implies) that if ' $\mathrm{X}$ ' is prohibited, then we can do everything except ' $\mathrm{X}$ '; and if ' $\mathrm{Y}$ ' is required, then we can do nothing but ' $\mathrm{Y}$ '. But that is obviously not correct. Firstly, ' $\mathrm{Y}$ ' is usually stated in a way that allows for several different things to count as 'doing Y'. If I see a child drowning, and I am required to offer assistance, my doing so may take the form of swimming out to save the child, or throwing a rope to her, or throwing out a buoy, or taking my boat over to her, or calling the lifeguard, or doing any other thing that counts as assisting the child. So it is not as if requiring me to do ' $\mathrm{Y}$ ' on pain of criminal sanction for not doing so reduces my options to precisely one. And secondly (and more importantly), we cannot assume that doing ' $\mathrm{Y}$ ' is incompatible with doing every other thing. I have never had to try, but I feel confident that I can lift a child out of two feet of water, while continuing to talk on the phone using my hands-free device, and holding my icecream in the other hand. I may not even need to break stride. I can also continue to enjoy the sun, or take in the fragrance of the nearby flowers, or do whatever else I was doing, so long as these other things are not incompatible with doing ' $\mathrm{Y}$ '. So requiring me to do ' $\mathrm{Y}$ ' means that I must do one of several things that amounts to ' $\mathrm{Y}$ ' and cannot do that subset of other things that is incompatible with doing ' $Y$ '. The gap between how liberty-limiting a prohibition on acting is as compared to a prohibition on omitting, is already a fair bit narrower than one might have initially assumed.

Even so, it is probably true that a general approach of criminally proscribing acts rather than failures to act would leave us with a greater number of open options. But I doubt that this generates any conclusive reason to have the AOD as a foundational concept in our criminal law.

Notice that the argument from liberty is not an argument about the AOD tout court - it is an argument about the consequences that follow from permitting the conviction of people based on their acts or omissions. Treating an omission as qualifying conduct is not a sufficient condition for convicting people based on the omission. As I previously 
pointed out, several other considerations supervene between an agent satisfying the conduct component of the actus reus of an offence and her conviction for the offence. Even if we treated all genuine omissions as satisfying the conduct component of various offences' actus reus elements, it is unlikely that we would significantly expand the net of criminal liability. The vast majority of cases in which we would previously acquit would probably still result in acquittals because of the absence of some other actus reus element, or the offence's mens rea, or because a defence is available. And even if empirically that were not the case, we would need some argument to demonstrate that the problem lay with how we specified the criminal law's conduct requirement, rather than how we specified the various other factors that affect a liability outcome. This point stands against each of the developments of the argument from liberty described above, since each systematically conflates 'treating omissions as conduct of interest to the criminal law' with 'convicting based on omissions'. However, for convenience, in what follows, I will not restate this objection when responding to each variant.

Another general point to bear in mind is that arguments from liberty rely on an implicit contingent claim about what consequences are acceptable to us. Nobody seriously argues that we should never prohibit omissions - of course an adequately liberty-respecting criminal law can prohibit some omissions. So the question is, how much liberty is too much liberty to forego in exchange for other values like security? The answer depends on the jurisdiction's societal mores: even western liberal democracies may differ amongst themselves. ${ }^{76}$

There are several different ways in which we can draft our criminal laws to achieve the desired balance between liberty and other desired values. 77 We could, for instance,

(a) adjust how much we expect of people ('Call the fire brigade!', rather than 'Run into a burning building to rescue someone!'), ${ }^{78}$ or

(b) require different things of people depending on the roles they occupy (in burning building scenarios, we expect more of firefighters than of laypersons), or

(c) adjust the threshold for the creation of a duty to act (the duty might arise only when acting would avert imminent serious

76 Consider for instance, that while most common law states do not have 'Good Samaritan' laws imposing any duty to make easy rescues, many civil law continental European states have these. Yet, all are liberal states.

77 Ashworth (n 7 above) 35.

78 Feinberg (n 8 above) 165. 
bodily harm, instead of when it might minimise eventual minor property damage), ${ }^{79}$ or

(d) adjust the threshold for accepting that failures to meet an expectation to act were justified or excused. Instead of insisting that such failures are only non-culpable if acting would have caused the agent serious bodily harm, we may grant a defence even when acting might have caused her minor property damage. Note that this last adjustment is relevant to resulting criminal liability, and not to the AOD tout court. Even so, it is relevant to our discussion of the trade-off between liberty and other desired values.

In fact, in general, our net expectations of other people are fairly undemanding. Therefore, 'criminalising omissions' to meet these expectations, would not be nearly as destructive to liberty as might be feared. Moreover, the liberty-limiting implications of doing so are also probably overestimated. 80 Consider that:

(a) It is at least arguable that liberty is not always intrinsically valuable. ${ }^{81}$ We may think that it is not valuable, or as valuable, to be free to engage in conduct in which we do not want to engage, or that is morally wrong. If such ideas appeal to us, then prohibiting some undesired and morally wrong omissions will have, at most, a limited effect on liberty.

(b) Duties to act (such as the duty to assist others in danger) are often shared amongst everyone who is similarly situated and practically capable of helping. Contrarily, duties not to do something are not shared like this. So, in this respect at least, duties to act are typically less demanding than duties not to act. 82

(c) Duties to act are usually temporally limited: one is only required to act - say, to make an easy rescue - for a short time, and only when specified circumstances arise. 83 On the other hand, duties to not act are usually permanent - one is never permitted to kill innocents. In this respect too, the difference between how much liberty is restricted by duties to act on the one hand, and duties not to act on the other, is smaller than one might have feared.

Consider now the other objections. Is it appropriate to give other people the power to create duties for us unilaterally and unexpectedly? This worry is premised on the mistaken assumption that our positive

79 Ashworth (n 7 above) 36.

80 Ibid 35-36.

81 Tadros (n 3 above) 200-203; Feinberg (n 8 above) 206-214.

82 Feinberg (n 8 above) 158-159, 163-165.

83 Tadros (n 3 above) 196-200; Ashworth (n 7 above) 35-36. 
obligations are generated only through choice. ${ }^{84}$ In fact, we create obligations for those around us without giving them a say in the matter from literally the moment that we are born. A child's birth means that the state needs to look out for the interests of one more person and intervene if the child's health and security is not adequately protected within the family. And the birth of younger siblings immediately places elder siblings under a moral duty, or at least a reasonable expectation (in Kleinig's sense), to look out for them. These duties to each other are what make us a society rather than a plurality of individuals. What's more, we are accustomed to having others unilaterally and unexpectedly create obligations for us. Each time an emergency vehicle sounds its siren, its driver unilaterally and unexpectedly creates obligations for everybody within earshot. So does every pedestrian who starts to cross a road, even when jaywalking. It seems to me that the fact that others can create obligations for me is not so much a problem, as it is a feature of living in a community of people. Of course, like most things, if others had too much power over our obligations that would be problematic. But we can guard against that by suitably crafting our omissions-based criminal liability (which recall, we can also do by adjusting other elements required for a criminal conviction, while leaving the conduct requirement intact).

Nor does criminalising failures to do good acts deprive us of our ability to freely choose to perform those acts and thereby alienate us from the goals we serve. That argument seems to overstate the criminal law's ability to crowd out other factors that influence our choices. It is hardly as if the only reason we choose not to go around killing people is that the criminal law tells us not to - our reasons for not offending are rarely connected to our criminal laws. ${ }^{85}$ Along the same lines, making omissions to do expected acts potentially liable to criminal consequences will not deprive us of our ability to do expected or good acts simply because they are expected or good. And our choices to do these acts will be no less good for our well-being because they happen to conform with the criminal law's expectations.

Finally, it is a mistake to think that 'criminalising omissions' to do things that we ought anyway to do makes it difficult to display virtue (at least any more than does criminalising the doing of things that we ought anyway not to do). Criminally enforced duties to act are rarely very demanding and, therefore, leave plenty of scope for displaying supererogatory virtue. Someone who thought that the criminal law contained all the moral and ethical guidance she needed would be terribly misguided indeed! 86

84 Ibid 196.

85 Ibid 204.

86 Ibid 204. 
In sum then, suitably crafted omissions-based criminal liability can leave us enough open options to be adequately liberty-respecting. This conclusion casts serious doubt on the ability of the argument from liberty to sustain the AOD in the conduct component of the actus reus of an offence. However we frame the criminal law's conduct requirement, we can probably still tweak the other preconditions for criminal convictions to ensure that our liability outcomes are adequately liberty-respecting.

\section{CONCLUSION}

The AOD is a fairly good rule of thumb, and, so long as one does not examine it too closely, it can be used to defend tenable conclusions. I have argued in this article, however, that on a closer examination it is less plausible, at least in the context of arguments about criminalisation. Provided we are careful to

(a) avoid conflating true omissions and mere non-doings,

(b) identify true omissions in a context-sensitive manner, and

(c) design our pairs of examples for comparison so as to exclude or equalise imbalances in extraneous factors such as mens rea states, defensive pleas, role responsibilities, the likelihoods of consequential harms, facts that add shock-value, and contingent systemic conditions

we have little reason to believe that an act is a better candidate for the conduct element of a potential criminal offence than an omission. In fact, when we compare acts and omissions carefully, it becomes clear that:

(a) the role that the conduct element plays in a criminal offence is a limited one, and a true omission seems as capable of playing that limited role as an act; and

(b) many of the apparent advantages of preferring to criminalise acts rather than omissions actually have little to do with the selection of the conduct-token. Instead, they arise independently from differences in other factors relevant to criminal liability.

The upshot of this is that we have reason to default to the view that the AOD should not influence our selection of a conduct-token for criminalisation. Moreover, a close consideration of the main lines of argument marshalled in support of the AOD - the arguments from authorship/responsibility, causation, wrongness/culpability, and liberty - reveals no compelling reason to abandon this default position.

It follows therefore, that the AOD does not deserve its foundational place in criminalisation theory. We do need the conduct element of 
the actus reus of an offence to transform a responsible moral agent's exercise of volitional control over her own conduct into a matter of interest to others, but instead of assuming that acts always perform this role, and omissions only exceptionally do so, we should consider each potential conduct-token on its own merits. 